\title{
Espresso Brownies
}

\author{
Jianni Adams
}

For trying to be impressive at parties

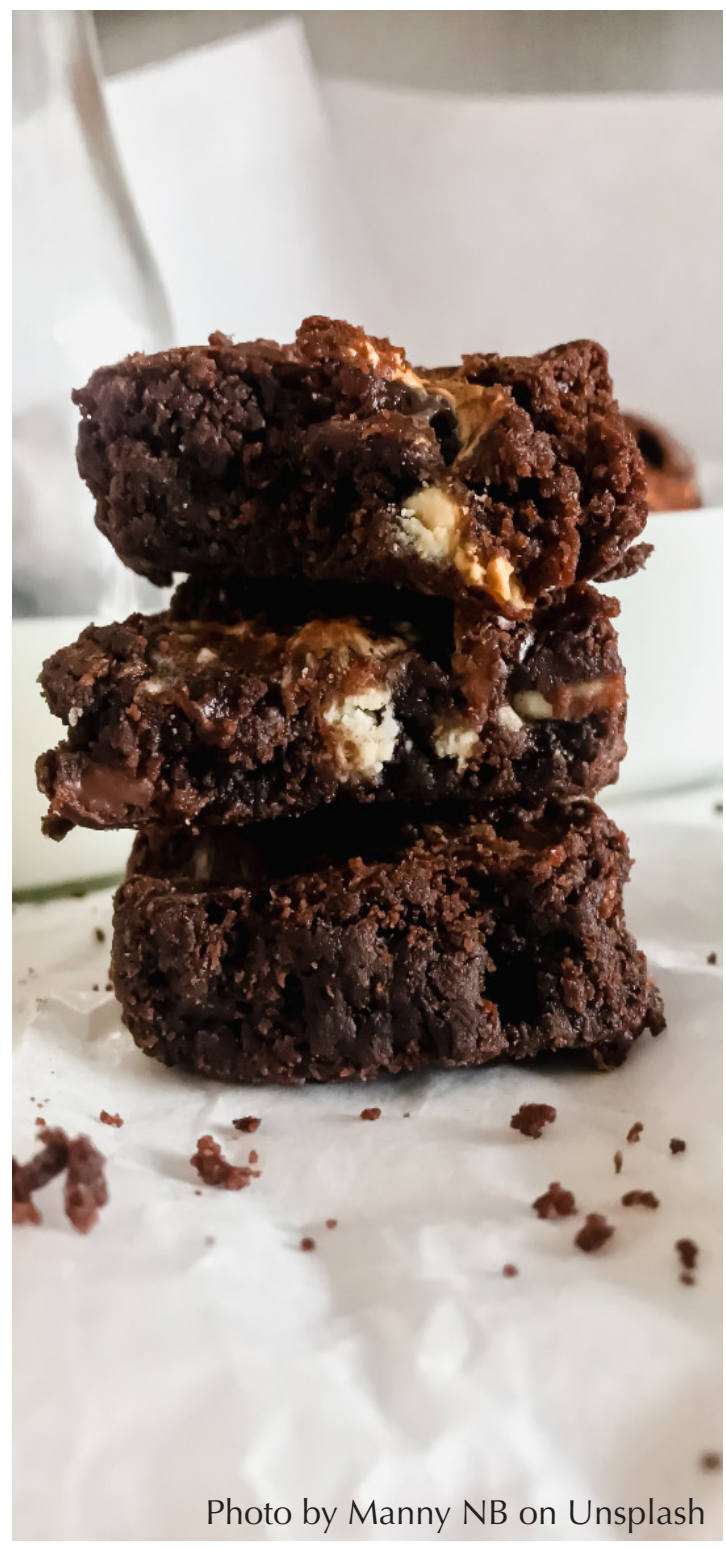

1. Box of desired brownie mix

2. Water source

3. Vegetable oil

4. An egg (or two)

5. Rusty kitchen scissors (to open the bagged mix)

6. Starbucks Via Packets

\section{Desired Result:}

A delicious homemade (Kind of? No? Okay.)

treat with hints oft he façade of domesticity ... and coffee.

Description: Stack of three chocolate brownies on white table. Brown crumbs are scattered on the table. Background is of a white curtain. 